\title{
MENENTUKAN HARGA KONTRAK BERJANGKA NILAI TUKAR RUPIAH TERHADAP DOLLAR AS MENGGUNAKAN DISTRIBUSI LOGNORMAL
}

\author{
Gede Sumendra $^{\S 1}$, Komang Dharmawan ${ }^{2}$, I Nyoman Widana ${ }^{3}$ \\ ${ }^{1}$ Jurusan Matematika, Fakultas MIPA - Universitas Udayana [Email: sumendragede@ yahoo.co.id] \\ ${ }^{2}$ Jurusan Matematika, Fakultas MIPA - Universitas Udayana [Email: dharmawan.komang@ gmail.com] \\ ${ }^{3}$ Jurusan Matematika, Fakultas MIPA - Universitas Udayana [Email: nwidana @ yahoo.com] \\ ${ }^{\S}$ Corresponding Author
}

\begin{abstract}
The purpose of this study is to determine the fair price of a futures contract for the IDR (Rupiah) against the USD using lognormal distribution simulation. This result is compared with interest rate parity theorem. The first step of this study is to determine the values of the parameters which are optimized using Maximum Likelihood Estimation (MLE). The parameters obtained in the form of the mean $(\mu)$ and variance $\left(\sigma^{2}\right)$. Further, parameters obtained are simulated using lognormal distribution to determine the exchange rate simulation $\left(S_{t}\right)$. Then price of future contract is also calculated using interest rate parity theorem. The price of the futures contracts $\left(F_{t}\right)$ is determined by lognormal distribution simulated and price of interest rate futures contracts using parity theorem. The results of this study show that future contract price over the fair use lognormal distribution of $R_{p}$ 12.215 compared to the interest rate parity theorem which $R_{p} 12.400$, with the initial contract price $\left(S_{0}\right)$ of $R_{p} 12.185$.
\end{abstract}

Keywords: derivatives, futures contracts, the exchange rate against the USD, lognormal distribution, interest rate parity theorem.

\section{PENDAHULUAN}

Pengertian pasar keuangan bukan hanya dapat diartikan sebagai tempat bertemunya penjual dan pembeli, namun pasar keuangan sudah dapat dijelaskan lagi secara spesifik seperti salah satunya adalah pasar keuangan derivatif. Pasar keuangan derivatif dikelompokkan berdasarkan sifat dari aktiva yang dijadikan sebagai induknya, seperti saham, obligasi, komoditas, dan berbagai macam indek. Pasar keuangan derivatif juga dapat dikelompokkan berdasarkan kontraknya antara lain future contracts, forward contracts, option contracts, swap contracts atau kombinasi dari beberapa kontrak sekaligus. Semua instrumen derivatif adalah kontrak antara dua pihak pembeli dan penjual yang di dalam kontraknya berbagai hal telah disepakati bersama pada saat ditetapkan, tetapi realisasinya atau pelaksanaan hal tersebut adalah nanti pada kurun waktu tertentu di masa yang akan datang. Salah satu dari kelompok derivatif tersebut adalah future contracts atau kontrak berjangka. Kontrak berjangka adalah perjanjian atau kesepakatan untuk membeli atau menjual aktiva tertentu pada saat tertentu atau pada harga tertentu dalam kurun waktu tertentu di masa yang akan dating (Siahaan [8]). Untuk mengurangi resiko yang terjadi pada proses ekspor dan impor luar negeri dengan valuta asing, sebagian besar perdagangan ekspor dan impor bersifat kontrak berjangka (Triyono [9]), artinya baru terlaksana beberapa bulan kemudian. Kontrak berjangka adalah kontrak yang bentuknya sudah dibuat baku, atau telah disekuritasi dan diperdagangkan di pasar tertentu. Kontrak ini dilakukan secara pribadi oleh dua belah pihak, tetapi dilakukan melalui bursa yang 
terorganisir. Berbicara tentang derivatif selalu berhubungan dengan kontrak yang ditandatangani pada kesepakatan yang telah dibuat oleh pembeli dan penjual dengan harga sekarang (harga yang sudah diketahui) dan harga antisipasi aktiva tertentu pada masa yang akan datang. Tercapainya kesepakatan kedua belah pihak antara pembeli dan penjual, tentunya harus terlebih dahulu dapat mengantisipasi biaya atau keuntungan yang akan didapatkannya. Pada umumnya pelaku pasar hanya akan menggunakan harga sekarang yang dipengaruhi oleh suku bunga, dan waktu untuk menghitung kontrak yang akan diperdagangkan. Namun cara tersebut sering kali menghasilkan harga yang tidak adil (fair), metode seperti ini merupakan cara yang biasa dipergunakan atau biasa disebut metode konvensional atau Interest rate parity theorem. Selain Interest rate parity theorem cara yang dapat dilakukan untuk mengantisipasi harga pada masa yang akan datang adalah dengan mensimulasikan harga awal dari kontrak berjangka tersebut. Simulasi yang dilakukan berkali-kali akan mendapatkan harga yang jauh lebih mendekati harga aslinya, sehingga harga yang didapat akan menjadi lebih adil. Salah satu metode untuk mensimulasikan harga kontrak berjangka adalah metode distribusi lognormal. Distribusi lognormal mempunyai bentuk yang tidak simetris dan merupakan salah satu bentuk distribusi yang sering digunakan untuk menghitung kerugian operasional. Suatu data kerugian operasional dikatakan berdistribusi secara lognormal, jika logaritma natural dari data kerugian tersebut terdistribusi secara normal. Berdasarkan latar belakang tersebut maka penulis ingin mengetahui bagaimana menentukan harga kontrak berjangka nilai tukar dengan menggunakan distribusi lognormal dan membandingkan harga kontrak berjangka nilai tukar dengan menggunakan Interest rate parity theorem.

\section{METODE PENELITIAN}

Penelitian yang akan dilakukan adalah studi kasus terhadap harga kontrak berjangka nilai tukar rupiah terhadap dollar AS. Peneliti ini akan mencari harga kontrak berjangka dari nilai tukar melalui perhitungan data harga penutupan (close) nilai tukar. Perhitungan yang dilakukan meliputi penentuan parameter yang diperlukan untuk menghitung harga kontrak berjangka, penentuan harga nilai tukar pada waktu $\mathrm{T}$ menggunakan simulasi Distribusi Lognormal, dan harga kontrak berjangka.

Langkah-langkah untuk menentukan harga kontrak berjangka dari suatu nilai tukar, yaitu: 1. Mempersiapkan dan menganalisis data nilai tukar yang akan digunakan; 2. Mencari tingkat pengembalian (return) dari data historis nilai tukar; 3. Menentukan parameter awal dari distribusi lognormal yaitu rata-rata $(\mu)$ dan varians $\left(\sigma^{2}\right)$ menggunakan metode moment; 4. Melakukan kalibrasi dengan nilai awal $\mu, \sigma^{2}$ menggunakan metode MLE dengan keluaran penduga $\widehat{\mu}, \widehat{\sigma^{2}} ;$ 5. Melakukan simulasi distribusi lognormal menggunakan parameterparameter $\left(\widehat{\mu}, \widehat{\sigma^{2}}\right)$ untuk menentukan nilai $S_{t}$; 6. Menghitung harga kontrak berjangka nilai tukar menggunakan simulasi distribusi lognormal; 7. Menghitung harga kontrak berjangka nilai tukar dengan Interest rate parity theorem; 8. Membandingkan harga kontrak yang didapat melalui simulasi Distribusi Lognormal dan harga kontrak dengan Interest rate parity theorem.

\section{HASIL DAN PEMBAHASAN}

\subsection{Harga Penutupan Harian (close price)}

Harga penutupan harian nilai tukar rupiah terhadap dollar AS dapat disajikan pada Gambar 1.

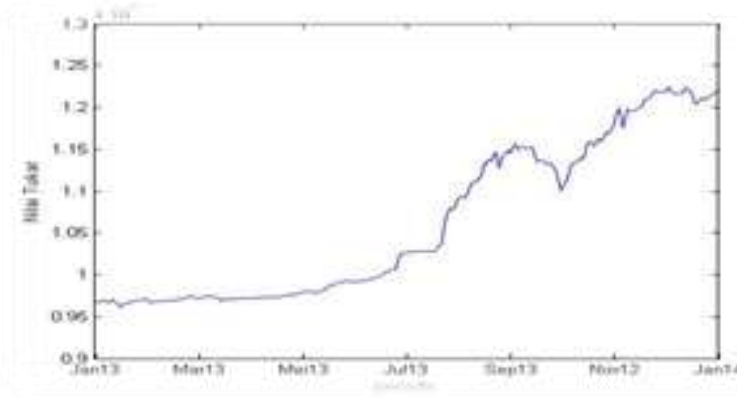

Gambar 1. Grafik Nilai Tukar Rupiah Terhadap Dollar AS Periode 28 Januari 2013 sampai 28 Januari 2014 
Berdasarkan Gambar 1 dapat diamati bahwa banyak terjadi lompatan-lompatan harga nilai tukar yang begitu ekstrem pada hari-hari tertentu, dan plot data nilai tukar (http://finance.yahoo.com/currency-investing) selama satu tahun ini memiliki tren harga yang naik.

\subsection{Variabel-variabel untuk Menentukan Harga Kontrak Berjangka}

Variabel yang digunakan untuk menentukan harga kontrak berjangka meliputi $S_{0}$ (harga nilai tukar awal), $T$ (waktu jatuh tempo opsi), $t$ (waktu), dan $r$ (suku bunga bebas risiko yang dikeluarkan oleh pihak yang berwenang di tempat melakukan transaksi kontrak berjangka). Nilai dari $S_{0}$ dapat dilihat pada data historis harga terakhir nilai tukar terbaru yaitu tanggal 28 Januari 2014 sebesar 12185 (http://finance.yahoo.com/currencyinvesting). Waktu jatuh tempo kontrak berjangka ditentukan selama tiga bulan, sedangkan untuk suku bunga bebas risikonya sebesar $7.5 \%$ yang dikeluarkan oleh bank Indonesia yang dapat dilihat pada alamat situs www.bi.go.id/id/Default.aspx.

\subsection{Menentukan Nilai Return}

Menentukan nilai $R_{i, t}$ (Return saham pada waktu $t$ ) dengan persamaan sebagai berikut:

$R_{i, t}=\ln \left(\frac{S_{i, t+1}}{S_{i, t}}\right)$

Data historis penutupan nilai tukar rupiah terhadap dollar AS yang didapat melalui situs (http://finance.yahoo.com/currency-investing).

Penghitungan yang akan dilakukan adalah menghitung nilai $R_{i, t}$ saat $t=1$ sebagai berikut:

$$
\begin{aligned}
R_{i, 1} & =\ln \left(\frac{9680}{9670}\right) \\
& =0,001034
\end{aligned}
$$

Untuk nilai $R_{i, t}$ terdapat pada Lampiran 2 yang dihitung dengan menggunakan software Matlab.

\subsection{Penentuan Nilai Mean, Varians, Skewnes, Kurtosis}

Nilai masukan deskriptif yang akan dicari dalam proses ini, didapat dengan memanfaatkan data nilai Return $\left(R_{i, t}\right)$ harga penutupan nilai tukar rupiah terhadap dollar AS yang terdapat pada Lampiran 2. Langkah yang akan dilakukan adalah menghitung nilai mean, varians, skewness, kurtosis dari nilai Return $\left(R_{i, t}\right)$ nilai tukar rupiah terhadap dollar AS dengan bantuan perintah program Matlab 7.8, sehingga didapat hasil pada Tabel 1 .

Tabel 1. Nilai Statistik Deskriptif untuk Model Distribusi Lognormal

\begin{tabular}{|c|c|}
\hline Parameter & Nilai \\
\hline Mean & 1.0009 \\
\hline Varians & -0.9982 \\
\hline Skewness & -0.1378 \\
\hline Kurtosis & 9.2902 \\
\hline
\end{tabular}

Dari Tabel 1 dapat dilihat bahwa Distribusi Lognormal memiliki bentuk yang tidak simetris, dilihat dari nilai skewness yaitu 0.1378 yang mengakibatkan data mencong (skew) ke kiri dan memiliki ekor gemuk (fat tail) dari nilai kurtosis yaitu 9.2902, yang normalnya 3 , disebabkan banyaknya data ekstrim pada data dan lompatan-lompatan harga (fluktuasi) muncul pada data nilai tukar. Taksiran parameter mean dan varians pada Tabel 1 akan dipakai sebagai pembangkit atau nilai awal dari proses pencarian parameterparameter yang optimal dalam metode MLE.

\subsection{Estimasi Parameter dengan MLE}

Parameter-parameter awal yang telah didapat pada Tabel 1 selanjutnya akan diestimasi untuk mendapatkan nilai parameterparameter proses Distribusi Lognormal dengan menggunakan MLE. Penentuan parameterparameter tersebut dapat dicari dengan menggunakan persamaan (2.20) dan (2.21). Dengan bantuan perintah program matlab 7.8. Diketahui bahwa $x_{i}$ adalah data nilai tukar periode 28 januari 2013 sampai 28 januari 2014 maka diperoleh nilai-nilai dari parameter 
Distribusi Lognormal sebagai berikut: Pertama penentuan nilai $\hat{\mu}$ melalui persamaan likelihood $\mathcal{L}(\pi)$ yang diturunkan terhadap $\mu$.

$$
\begin{aligned}
\frac{\partial L}{\partial \mu} & =\frac{\sum_{i=1}^{n} \ln \left(x_{i}\right)}{\widehat{\sigma^{2}}}-\frac{n \hat{\mu}}{\hat{\sigma}^{2}}=0 \\
\hat{\mu} & =\frac{\sum_{i=1}^{n} \ln \left(x_{i}\right)}{n} \\
& =\frac{0+0.001034+\cdots+(-0.00328)}{262} \\
& =\frac{0.231177}{262} \\
& =0.000885737
\end{aligned}
$$

Kedua penentuan nilai $\hat{\sigma}^{2}$ melalui persamaan likelihood $\mathcal{L}(\pi)$ yang diturunkan terhadap $\sigma^{2}$.

$$
\begin{aligned}
\frac{\partial L}{\partial \sigma^{2}} & =-\frac{n}{2} \frac{1}{\sigma^{2}}-\frac{\sum_{i=1}^{n}\left(\ln \left(x_{i}\right)-\hat{\mu}\right)^{2}}{2}\left(-\hat{\sigma}^{2}\right)^{-2}=0 \\
\hat{\sigma}^{2} & =\frac{\sum_{i=1}^{n}\left(\ln \left(x_{i}\right)-\hat{\mu}\right)^{2}}{n} \\
& =\frac{\sum_{i=1}^{262}\left(\ln \left(x_{i}\right)-0.000885737\right)^{2}}{262} \\
& =0.0000137
\end{aligned}
$$

Nilai-nilai dari mean $(\mu)$ dan varians $\left(\sigma^{2}\right)$ disajikan dalam Tabel 2

Tabel 2. Nilai Parameter Distribusi Lognormal Menggunakan MLE

\begin{tabular}{|c|c|}
\hline Parameter & Distribusi Lognormal \\
\hline Mean $(\hat{\mu})$ & 0.000885737 \\
\hline Varians $\left(\hat{\sigma}^{2}\right)$ & 0.0000137 \\
\hline
\end{tabular}

Nilai parameter Distribusi Lognormal pada Tabel 2 tersebut akan digunakan untuk mensimulasikan harga nilai tukar rupiah terhadap dollar AS.

\subsection{Simulasi Distribusi Lognormal}

Simulasi Distribusi Lognormal akan mengikutsertakan pembangkitan bilangan acak. Algoritma ini memerlukan pengulangan (repetisi) dan perhitungan yang amat kompleks, sehingga umumnya dilakukan dengan menggunakan komputer. Simulasi ini diproses melalui banyak iterasi dengan variabel acak yang berbeda dan untuk memperkirakan nilai dari nilai tukar rupiah terhadap dollar AS yang akan datang dengan merata-ratakan kemungkinan yang terjadi.
Dimana dilakukan beberapa simulasi kemudian harga nilai tukar yang akan didapat, diperoleh dengan merata-ratakan simulasi yang terjadi.

Simulasi dilakukan dengan memasukkan nilai-nilai dari parameter Distribusi Lognormal melalui kalibrasi parameter-parameter awal yaitu mean $(\hat{\mu})$ dan varians $\left(\hat{\sigma}^{2}\right)$ pada Tabel 2 ke dalam perintah pada program Matlab 7.8. Simulasi yang akan dilakukan dijalankan dengan menggunakan harga awal $S_{t}$ sebesar 12.185 dan dalam jangka waktu kontrak selama 3 bulan. Agar pengamatan lebih mudah dilakukan, maka simulasi yang akan ditampilkan hanya sebatas 5 kali simulasi, yang disajikan dalam bentuk grafik pada Gambar 2. Akan tetapi pada penelitian ini hasil yang dipergunakan adalah hasil dari simulasi yang dijalankan sebanyak 100.000 simulasi yang dapat dilihat pada Tabel 3 .

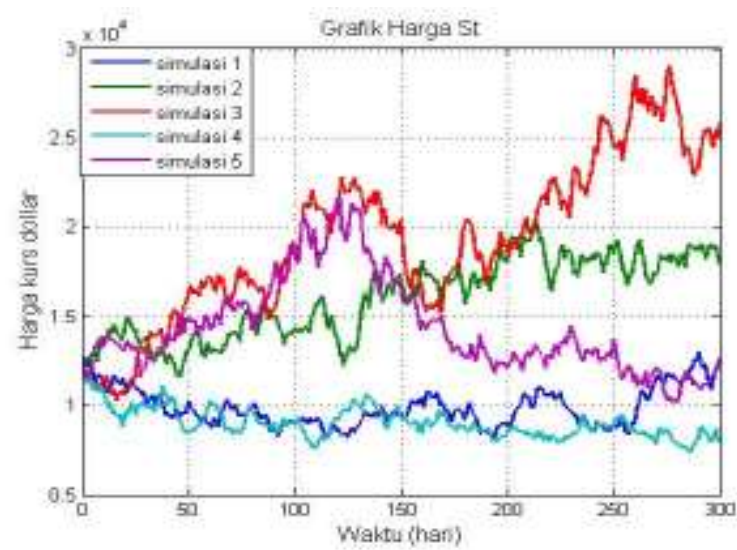

Gambar 2. Grafik Harga $\left(S_{t}\right)$ sebanyak 5 kali simulasi

Pada Gambar 2 dapat dilihat bahwa simulasi yang dilakukan sebanyak 5 kali simulasi akan menghasilkan 5 grafik nilai tukar $\left(S_{t}\right)$, dan masing-masing dari grafik nilai tukar $\left(S_{t}\right)$ pada Gambar 3 menghasilkan 3 bulan nilai tukar $\left(S_{t}\right)$ yang diakibatkan oleh lamanya kontrak yang dijalankan. Kelima grafik nilai tukar $\left(S_{t}\right)$ pada Gambar 3 ditunjukkan oleh simulasi 1, simulasi 2, simulasi 3, simulasi 4, dan simulasi 5. Masing-masing dari kelima grafik nilai tukar $\left(S_{t}\right)$ pada Gambar 2 akan dicari nilai rata-ratanya sehingga akan menghasilkan nilai tukar rata-rata $\left(S_{t}\right)$. Selanjutnya dari nilai tukar rata-rata tersebut 
akan digunakan untuk mencari nilai tukar kontrak berjangka $\left(F_{t}\right)$.

\subsection{Penentuan Kontrak Berjangka Nilai Tukar Rupiah Terhadap Dollar AS}

Penentuan kontrak berjangka nilai tukar pada penelitian ini akan dicari menggunakan dua metode, yaitu dengan metode simulasi Distribusi Lognormal dan Interest Rate Parity Theorem. Kemudian hasil yang didapat dari kedua metode itu akan dipilih mana yang lebih adil dalam penentuan kontraknya

a) Penentuan Kontrak Berjangka Nilai

tukar Rupiah terhadap dollar AS menggunakan Simulasi Distribusi Lognormal

Nilai kontrak berjangka nilai tukar $\left(F_{t}\right)$ akan dicari menggunakan harga nilai tukar $\left(S_{t}\right)$ yang telah didapatkan melalui simulasi Distribusi Lognormal pada Gambar 2. Nilai $S_{t}$ rata-rata yang didapat, akan dimasukkan pada persamaan (2.2) dengan nilai $(e)$ sebesar 2,718281828 dan suku bunga bebas resiko $(r)$ sebesar 7,5\% yang dikeluarkan oleh bank Indonesia, sehinggga akan didapat harga $F_{t}$ yang merupakann harga akhir kontrak yang dicari. Pada Tabel 4 akan diperlihatkan untuk harga kontrak berjangka yang dilakukan dengan jumlah simulasi yang lebih banyak yang dijalankan pada program Matlab dan harga kontrak yang akan digunakan dalam penelitian ini adalah harga kontrak dengan simulasi sebanyak 100.000 simulasi, karena semakin banyak simulasi yang akan dilakukan maka nilai yang di dapat akan semakin konvergen ke harga aslinya.

Tabel 3. Nilai Kontrak Berjangka Menggunakan Simulasi Distribusi Lognormal

\begin{tabular}{|c|c|c|}
\hline $\begin{array}{c}\text { Jumlah } \\
\text { simulasi } \\
\text { (kali) }\end{array}$ & $\begin{array}{c}\text { Harga } \\
\text { Simulasi Nilai } \\
\text { tukar (St) }\end{array}$ & $\begin{array}{c}\text { Harga } \\
\text { Kontrak } \\
\text { Berjangka } \\
(\mathrm{Ft})\end{array}$ \\
\hline 5 & 12.385 & 12.619 \\
\hline 10 & 12.183 & 12.413 \\
\hline 50 & 12.175 & 12.405 \\
\hline 100 & 12.169 & 12.333 \\
\hline 1000 & 12.111 & 12.325 \\
\hline 10000 & 12.141 & 12.310 \\
\hline 100000 & 12.032 & 12.215 \\
\hline
\end{tabular}

\section{b) Penentuan Kontrak Berjangka Nilai tukar Rupiah terhadap dollar AS menggunakan Interest Rate Parity Theorem.}

Penentuan harga kontrak berjangka nilai tukar rupiah terhadap dollar AS menggunakan Interest rate parity theorem, hanya melibatkan parameter-parameter seperti harga awal nilai tukar, tingkat suku bunga bebas resiko, dan waktu. Sehingga dalam perhitungannya dapat dihitung menggunakan persamaan (2.2). Dari data historis nilai tukar pada lampiran I, telah diketahui nilai-nilai masukan yang akan dipakai dalam penentuan kontrak berjangka nilai tukar seperti harga awal $\left(S_{0}\right)$ yang merupakan harga terakhir dari data sebelum kontrak tersebut dibuat, $(r)$ yang merupakan suku bunga bebas resiko sebesar 7,5\% yang dikeluarkan oleh bank Indonesia, $\left(r_{U S}\right)$ yang merupakan suku bunga di negara Amerika Serikat sebesar 0,25\% yang dapat dilihat pada alamat situs

(http://www.fxstreet.web.id/economiccalendar/interest-rates-table/) dan ( $t)$ yang merupakan waktu berlangsungnya kontrak selama 3 bulan atau 0,25 tahun

Tabel 4. Nilai Masukan untuk Menentukan Kontrak Berjangka Menggunakan Interes Rate Parity Theorem

\begin{tabular}{|c|c|}
\hline Nilai masukan & Distribusi Lognormal \\
\hline$S_{0}$ & 12.185 \\
\hline$r$ & 0,075 \\
\hline$r_{U S}$ & 0,0025 \\
\hline$t$ & 0,25 \\
\hline
\end{tabular}

Perhitungan harga kontrak berjangka nilai tukar rupiah terhadap dollar AS menggunakan Interest rate parity theorem.

$$
\begin{aligned}
F_{t} & =S_{0}\left(\frac{1+r_{x}}{1+r_{y}}\right)^{t} \\
F_{t} & =12.185\left(\frac{1+0,075}{1+0,0025}\right)^{0,25} \\
& =12.400
\end{aligned}
$$


Dengan menggunakan interest rate parity theorem maka hasil dari kontrak berjangka nilai tukar rupiah terhadap dollar AS yang didapat adalah sebesar 12.400

\subsection{Perbandingan Nilai kontrak Berjangka Nilai Tukar Rupiah Terhadap Dollar AS Menggunakan Simulasi Distribusi Lognormal dengan Interest Rate Parity Theorem}

Dalam membandingkan nilai kontrak berjangka nilai tukar rupiah terhadap dollar AS menggunakan simulasi Distribusi Lognormal dengan Interest rate parity theorem akan ditunjukkan pada Tabel 5.

Tabel 5. Perbandingan Nilai Kontrak Berjangka Nilai Tukar Rupiah Terhadap Dollar AS

\begin{tabular}{|c|c|c|}
\hline $\begin{array}{c}\text { Waktu } \\
\text { Kontrak } \\
\text { Berjangka }\end{array}$ & $\begin{array}{c}\text { Simulasi } \\
\text { Distribusi } \\
\text { Lognormal }\end{array}$ & $\begin{array}{c}\text { Interest Rate } \\
\text { Parity } \\
\text { Theorem }\end{array}$ \\
\hline 1 bulan & 12.095 & 12.256 \\
\hline 2 bulan & 12.191 & 12.328 \\
\hline 3 bulan & 12.215 & 12.400 \\
\hline
\end{tabular}

Berdasarkan hasil yang telah didapat pada Tabel 5 dapat dilihat ada perbedaan nilai yang dihasilkan dalam penentuan harga kontrak berjangka nilai tukar menggunakan simulasi Distribusi Lognormal dan Interest Rate Parity Theorem. Dengan simulasi Distribusi Lognormal harga kontrak yang dihasilkan lebih mendekati harga kontrak nilai tukar sebesar $R_{p} 12.215$, sedangkan Interest Rate Parity Theorem menghasilkan harga kontrak sebesar $R_{p} 12.400$, dengan harga kontrak awal sebesar $R_{p} 12.185$.

\section{KESIMPULAN}

Berdasarkan hasil dan pembahasan dapat disimpulkan:

1. Diperoleh harga kontrak berjangka nilai tukar selama 3 bulan yang dihitung menggunakan simulasi Distribusi Lognormal sebesar $R_{p} 12.185$, sedangkan Interest Rate Parity Theorem menghasilkan harga kontrak nilai tukar sebesar $R_{p} 12.400$.
2. Harga kontrak nilai tukar yang dihitung menggunakan simulasi Distribusi Lognormal adalah $R_{p} 12.185$, sehingga harga kontrak nilai tukar yang diperoleh menggunakan simulasi Distribusi Lognormal mendekati harga kontrak nilai tukar aktual sebesar $R_{p} 12.185$, sedangkan Interest Rate Parity Theorem menghasilkan harga kontrak nilai tukar sebesar $R_{p} 12.400$.

\section{DAFTAR PUSTAKA}

[1] Boediono, 1998. Ekonomi Moneter. edisi 3, BPFE: Yogyakarta

[2] Brigo D., Dalessandro A., Neugebauer M., Triki F. (2009) "A stochastic processes toolkit for risk management: jumps, GARCH and variance gamma models" Journal of Risk Management in Financial Institutions, 2, 4, 365-393

[3] Harinaldi, M., 2005. Prinsip-Prinsip Statistik umtuk Teknik dan Sains, Editor Lameda Simarmata, Penerbit Erlangga.

[4] Mastro, M., 2013. Financial Derivative and Energi Market Valuation. Canada: Jhon Wiley \& Sons, Inc.,Hoboken, New Jersey

[5] Norstad, J., 1999. The Normal and Lognormal Distributions.

[6] Redhead, K., 1997. Financial Derivatives: An Introduction to Futures, Forwards, Options and Swaps. London: Prentice-Hall

[7] Kapur, J.N. and Saxena, H.C., 1960. Mathematical Statistics. New Delhi: S. Chand \& company LTD.

[8] Siahaan, H., 2008. Seluk-Beluk Perdagangan Instrumen Derivatif. Jakarta: PT Elex Media Komputindo.

[9] Tryono, 2008. Analisis Perubahan Kurs Rupiah terhadap Dollar Amerika. jurnal ekonomi pembangunan, 9(2), pp. 156-167

[10]Walpole, R. E., 1995. Pengantar Statistika. edisi 3. Jakarta: Gramedia 